Neurosurg Focus 19 (5):E5, 2005

\title{
The molecular epidemiology of gliomas in adults
}

\author{
Margaret Wrensch, Ph.D., James L. Fisher, Ph.D., Judith A. Schwartzbaum, Ph.D., \\ Melissa Bondy, Ph.D., Mitchel Berger, M.D., And Kenneth D. AldaPe, M.D.
}

\begin{abstract}
Department of Neurological Surgery, University of California, San Francisco, California; The Arthur G. James Cancer Hospital and Richard J. Solove Research Institute; The Ohio State University Comprehensive Cancer Center; Division of Epidemiology and Biometrics, School of Public Health, The Ohio State University, Columbus, Ohio; Institute of Environmental Medicine, Karolinska Institute, Stockholm, Sweden; Departments of Epidemiology and Pathology and Brain Tumor Center, The University of Texas M. D. Anderson Cancer Center, Houston, Texas
\end{abstract}

\begin{abstract}
In this paper the authors highlight recent findings from molecular epidemiology studies of glioma origin and prognosis and suggest promising paths for future research. The reasons for variation in glioma incidence according to time period of diagnosis, sex, age, ancestry and ethnicity, and geography are poorly understood, as are factors that affect prognosis. High-dose therapeutic ionizing irradiation and rare mutations in highly penetrant genes associated with certain rare syndromes - the only two established causes of glioma — can be called upon to explain few cases. Both familial aggregation of gliomas and the inverse association of allergies and immune-related conditions with gliomas have been shown consistently, but the explanations for these associations are inadequately developed or unknown. Several biomarkers do predict prognosis, but only evaluation of loss of $1 \mathrm{p}$ and $19 \mathrm{q}$ in oligodendroglial tumors are incorporated in clinical practice. Ongoing research focuses on classifying homogeneous groups of tumors on the basis of molecular markers and identifying inherited polymorphisms that may influence survival or risk. Because most cases of glioma have yet to furnish either an environmental or a genetic explanation, the greatest potential for discovery may lie in genomic studies in conjunction with continued evaluation of environmental and developmental factors. Large sample sizes and multidisciplinary teams with expertise in neuropathology, genetics, epidemiology, functional genomics, bioinformatics, biostatistics, immunology, and neurooncology are required for these studies to permit exploration of potentially relevant pathways and modifying effects of other genes or exposures, and to avoid false-positive findings. Improving survival rates for patients harboring astrocytic tumors will probably require many randomized clinical trials of novel treatment strategies.
\end{abstract}

KEY WORDS
survival $\bullet$ prognosis

Molecular epidemiology integrates molecular technologies and ideas into epidemiological studies of disease origins and outcomes. The translational goals of such research are to understand a disease sufficiently to enable the development of strategies to reduce the patient population burden. With respect to glioma origin and survival rates for adults, approaches based on molecular epidemiology have been used to classify glial tumors into more homogeneous categories, to study the roles of common genetic polymorphisms, and to identify biomarkers related to developmental or environmental risk factors for gliomas. Because there have been several recent reviews of brain tumor epidemiology and pathogenesis, we refer interested readers to these papers for details. , $^{8,74,7,78,115,123,183}$ The purpose here is to provide the context for molecular epidemiology studies of gliomas, to highlight recent findings, and to suggest promising paths for future research.

Abbreviations used in this paper: $\mathrm{CI}=$ confidence interval; $\mathrm{CYP}=$ cytochrome P-450; EGFR = epidermal growth factor receptor; GBM = glioblastoma multiforme; GST = glutathione $S$-transferase; $\mathrm{IL}=$ interleukin; $\mathrm{OR}=$ odds ratio.

\section{Impact and General Epidemiology of Gliomas}

The term "glioma" refers to tumors thought to be of glial cell origin and includes astrocytic tumors (World Health Organization astrocytoma classification of Grades I, II [astrocytoma], III [anaplastic astrocytoma], and IV [GBM]), oligodendrogliomas, ependymomas, and mixed gliomas. ${ }^{28,88,99}$ Approximately 13,000 deaths and 18,000 new cases of primary malignant brain and central nervous system tumors occur annually in the US; approximately $77 \%$ of these are brain gliomas. ${ }^{28}$ Primary brain and central nervous system tumors rank first among cancer types for the average years of life lost, with an average of 20.1 years (compared, for example, with 6.1 years for prostate cancer and 11.8 years for lung cancer). ${ }^{21}$ Survival from GBM, the most common form of glioma in adults, is poor; with median survival time approximately 3.5 months for patients 65 years or older at diagnosis and only 10 months for those under 65 years, according to data collected by the Surveillance Epidemiology and End Results Program. ${ }^{38}$ Approximately 2\% of patients 65 years of age or older and only $30 \%$ of those young- 
er than 45 years at GBM diagnosis survive for 2 years. ${ }^{28}$ Furthermore, although survival rates for individuals with GBM have shown no notable improvements in population statistics for more than 30 years, ${ }^{38}$ recent clinical trial data on the use of combined radiotherapy and temozolomide found a median survival period of 14.6 months compared with 12 months for patients treated with radiotherapy alone. ${ }^{154}$

\section{GENERAL MOLECULAR PATHOLOGICAL NATURE OF GLIOMAS}

\section{Commonly Altered Chromosomal Regions}

Classic cytogenetic and array-based comparative genomic hybridization studies of gliomas have identified copy number changes (deletions, amplifications, and gains) in several regions; deletions and loss of heterozygosity in tumors may indicate genes involved in tumor suppression, whereas amplifications and gains may point to genes involved in tumor initiation or progression (for example, oncogenes). The more regularly observed of these changes, which may vary by histological type, as well as some candidate genes in the regions include gains and deletions in $1 \mathrm{p}$ (1p36.31-pter, 1p36.22-p36.31, and p34.2-p36.1), gains in 1q32 (RIPK5, MDM4, PIK3C2B, and others), deletion of 4q (NEKI and NIMA), amplifications and gains in chromosome 7 (7p11.2-p12, EGFR), deletions in chromosome 9 (9p21-p24, CDKN2), deletions in chromosome 10 (10q23, PTEN; 10q25-q26, MGMT), deletions in chromosome 11 (11p [between CDKNIC and RRAS2]), amplifications of 12 (12q13.3-q15, MDM2, CDK4, and many others), loss of 13 (13p11-p13 and 13q14-q34, RB1), loss of 19 (19q13, GLTSCR1, GLTSCR2, LIG1, PSCD2, and numerous others), loss of 22 (the 22q11.21-12.2 region has 28 genes including INI1, known for its involvement in rhabdoid tumors, and q13.1-13.3). These issues are reviewed by Ichi-

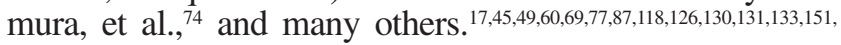
${ }^{155,156}$ This brief summary demonstrates that although several well-known tumor suppressor genes and oncogenes occur in these regions, many genes in the regions have yet to be identified for their specific relationship to glioma genesis.

\section{Dysregulated Pathways in Astrocytic Gliomas}

Classic molecular and cytogenetic studies of tumors as well as the newer array-based assays of comparative genomic hybridization and RNA expression indicate substantial heterogeneity of genes and gene expression within and between histological grades of astrocytic tumors and between different histological types of gliomas. . $^{51,74,89,94,113 \text {, }}$ ${ }_{114,128}$ It has become increasingly apparent that such heterogeneity at the cellular level reflects the action of different causal mechanisms in the pathogenesis of the disease. Because astrocytic gliomas compose more than $70 \%$ of all adult gliomas, we emphasize pathways known to be important for these tumors and do not provide a comprehensive review here of this rapidly expanding area of research. The phenotype called GBM arises from dysregulation of several different pathways. Dysregulation can occur from a variety of genetic and epigenetic mechanisms, including gene mutation, amplification, deletion, methylation or demethy- lation, whole or partial chromosome gains or losses, and transcriptional interference. . $^{4,82,88-90,177}$ Several interrelated pathways are well established as being dysregulated in GBM and other gliomas. Recurring themes are that these pathways are involved in cell-cycle signaling and control (proliferation and apoptosis), cytoskeleton regulation, transcription, growth signaling, cell adhesion, migration, and cytokine response (Table 1). ${ }^{74}$

\section{Molecular Pathways to GBM}

Progress has been made with respect to elucidating the genetic pathways that lead to GBMs. It is now believed that these tumors arise by two pathways that can be defined in clinical terms: one pathway results from tumor progression from lower-grade astrocytomas ("secondary" GBM) and a second pathway has no clinically evident precursor ("primary" or "de novo" GBM). Interestingly, examination of two molecular aberrations, TP53 mutation and EGFR amplification, has led to their correlation with the type of GBM defined on a clinical basis. ${ }^{94,164}$ Specifically, tumors with TP53 mutations are more likely to be secondary GBMs, arising from lower grade precursors, whereas a de novo GBM is more likely to harbor EGFR amplification. Although this distinction is not absolute and has recently been called into question, ${ }^{116}$ it raises the possibility that distinct subtypes of GBM may be similar histologically yet display clinical differences, specifically in response to therapeutic agents. Molecular subtyping is currently not routine but is likely to be of use in the future as an adjunct to histological analysis in the classification of these tumors.

\section{Population Studies of Tumor Markers in Astrocytic Gliomas}

To date only two studies have presented data on genetic and molecular tumor markers for relatively large numbers of population-based glioma cases. ${ }^{114,177}$ Although in each study five or six tumor markers were assessed, only two (EGFR amplification and TP53 mutation) were measured in both studies. Interestingly, the percentage of GBMs with EGFR amplification was identical in the two studies (36\% of 371 de novo GBMs from Zurich and $36 \%$ of 386 GBMs from the San Francisco Bay area). The percentage of tumors with a TP53 mutation varied from $28 \%$ of 386 GBMs from Zurich to only $15 \%$ of 409 GBMs from San Francisco; percentages in clinical series have ranged from 20 to $30 \%{ }^{81}$ Despite some inconsistencies, these findings support the hypothesis, proposed in smaller clinical series, that astrocytic tumors may arise through different pathways and may reflect the action of different causal mechanisms. To summarize current findings for astrocytic tumors, TP53 tumor mutations are associated with a younger age at diagnosis and are more common in lower-grade tumors and in GBMs arising from them; $; 2,89,114,127,177$ TP53 tumor mutations are more common in non-Caucasians, whereas tumors overexpressing EGFR or containing p16 deletions are more common in Caucasians; ${ }^{106,177}$ MGMT 84Phe carriers are overrepresented among GBM cases in which tumors do not overexpress TP53 protein; ${ }^{177}$ and the GSTT1 constitutive deletion is more common among GBM cases in which the tumor displays the TP53 mutation. ${ }^{181}$ 
Molecular epidemiology of gliomas in adults

TABLE 1

Pathways dysregulated in GBM and other gliomas*

\begin{tabular}{|c|c|}
\hline Important Pathways & Pathway Functions and Effects \\
\hline$R b / p 16 / p 15 / C D K 4 /$ & cell cycle checkpoint pathway controlling \\
\hline CyclinD & $\begin{array}{l}\text { DNA-dependent transcription; under } \\
\text { the influence of receptor-dependent } \\
\text { growth factors signals cell proliferation } \\
\text { through influence on S-phase genes \& } \\
\text { TP53 pathways by stimulating } p 14 A R F\end{array}$ \\
\hline TP53/MDM2/p14ARF & $\begin{array}{l}\text { cell cycle arrest; apoptosis; dysregulation } \\
\text { enhances cell proliferation, which } \\
\text { combined w/ apoptotic failure leads to } \\
\text { genomic instability }\end{array}$ \\
\hline EGF/EGFRPDGFalphaR & $\begin{array}{l}\text { growth signaling stimulates cell proliferation, } \\
\text { focal adhesion, MAPK (mitogen } \\
\text { activated protein kinase) signaling, } \\
\text { calcium signaling, actin cytoskeleton } \\
\text { regulation, \& cytokine-cytokine } \\
\text { receptor interactions }\end{array}$ \\
\hline Ras/RafIMAPK & $\begin{array}{l}\text { pleiotropic effectors of cell physiology } \\
\text { involved in gene expression, cell } \\
\text { cycle, apoptosis, cell differentiation, } \\
\& \text { cell migration }\end{array}$ \\
\hline PI3-kinase/AKT & $\begin{array}{l}\text { pleiotropic effectors preventing apoptosis } \\
\& \text { influencing focal adhesion, } M A P K \\
\text { signaling, tight junction, and Toll-like } \\
\text { receptor signaling }\end{array}$ \\
\hline$W N T$ signaling & $\begin{array}{l}\text { cell cycle control, TGF- } \beta \text {; other } \\
\text { components of WNT signaling affect } \\
\text { focal adhesion, cytoskeletal change, } \\
\& \text { gene transcription }\end{array}$ \\
\hline$H I F 1-\alpha / V E G F$ & response to hypoxia/angiogenesis \\
\hline PTEN & $\begin{array}{l}\text { pleiotropic effector involved in focal } \\
\text { adhesion, phosphatidylinositol signaling } \\
\text { system (suppresses PI3-kinase/AKT activa- } \\
\text { tion), tight junction }\end{array}$ \\
\hline
\end{tabular}

* Summarized from Ichimura, et al., with additional information from http: //www.ncbi.nlm.nih.gov/entrez/query.fcgi?CMD=search\&DB=gene.

\section{SURVIVAL RATES AND PROGNOSIS FOR PATIENTS WITH GLIOMAS}

Information on survival rates and prognosis for patients with gliomas comes from clinical trials and population registry data. Studies from the Radiation Therapy Oncology Group and other clinical trial groups provide useful information on prognostic factors from cases whose pathological features have been centrally reviewed and for patients who qualify for and are treated in clinical trials. Because the majority of patients do not enter clinical trials, however, the results might not be applicable to or representative of the general population of patients with gliomas. Survival rate estimates based on population registry data can represent the full spectrum of patients in whom gliomas are diagnosed, yet pathological diagnoses are subject to considerable variability depending on numerous factors, including the pathologist's neuropathological training ${ }^{1}$ and the time and place the diagnosis was made. ${ }^{35,83}$ Also, population registries do not generally have treatment data as extensive as that available from clinical trials.

Histological type and grade of tumor, patient age, extent of lesion resection, tumor location, whether the patient undergoes radiation therapy, and some chemotherapy protocols have been consistently and convincingly linked to sur- vival in both population registry and clinical trial data. ${ }^{29,36}$, 38,39,66,93,96,141,142 The Karnofsky Performance Scale score at diagnosis and other measures of mental and physical functionality also predict survival for patients with GBMs and anaplastic astrocytomas enrolled in the Radiation Therapy Oncology Group and other multiinstitutional clinical trials. ${ }^{36,93,141}$

In addition to these factors, investigators are currently trying to identify and understand tumor markers or patient characteristics that might influence survival or response to treatment; ${ }^{10,25,51,53,92,97,113,117,125,137,144,146,158,170,189}$ specific examples are presented later in this paper. A key unsolved problem in neurooncology is the strong and consistent inverse relationship of age to survival. The reasons, whether they pertain to properties related to the tumor or the host, are not well understood. The response of tumors to radiation has been reported to be poorer in older patients. ${ }^{5}$ In this regard, one contributing factor may be related to different frequencies of molecular or chromosomal aberrations among tumors in older patients compared with those in younger patients (a topic that will be discussed subsequently). One difficulty in identifying prognostic factors in rapidly fatal gliomas such as GBMs may be related to the narrow range of survival time experienced by the vast majority of patients. One method to address this limitation is to compare tumors from rare long-term survivors with those from typical GBM survivors. Studies performed at the University of Texas M. D. Anderson Cancer Center, using both a candidate gene approach ${ }^{23}$ and a genome-wide screen, ${ }^{22}$ have indicated that differences exist between tumors obtained in long-term survivors and those obtained from typical GBM survivors. ${ }^{22}$ Although such studies may not be as easily extended to clinical use as prognostic markers, they point to aberrations that may be responsible for the nearly uniformly poor prognosis for patients with GBM.

\section{Studies of Tumor Markers in Relation to Survival}

Combined losses of $1 \mathrm{p}$ and $19 \mathrm{q}$ in oligodendroglial tumors are well-established favorable prognostic indicators. ${ }^{25,49,50,61,70,76,87,148,149,161}$ In astrocytic tumors, amplification/ overexpression of EGFR is more common in older patients, especially those with anaplastic astrocytoma; ${ }^{177}$ this amplification/overexpression may also contribute to resistance to therapeutic modalities. ${ }^{6,191}$ Although EGFR amplification is more common in tumors from older individuals, it is not exclusive to that age group and may be associated with poor survival rates in younger $(<55-60$ years of age) adults with GBM. ${ }^{146,150}$ A subset of tumors with $E G F R$ amplification demonstrates an additional change in the EGFR gene resulting from an internal rearrangement called EGFRvIII. Although the results of large studies have yet to be reported, the presence of the EGFR $I I I$ allele may also be a negative prognostic factor. ${ }^{48,64}$ Data from a recent large prospective trial of patients with newly diagnosed GBMs have indicated that methylation of the MGMT promoter in GBM tumor samples was a marker of improved outcome, as measured by the 2-year survival rate. ${ }^{154}$ Interestingly, MGMT methylation appeared to be much more strongly associated with survival among patients who received frontline temozolomide than among those who did not, ${ }^{63}$ raising the possibility that $M G M T$ methylation may be a predictive marker of response to this alkylating agent. 


\section{Insights From Expression Array Studies of Gliomas}

In two recent studies the investigators assessed the prognosis for patients with gliomas from expression profiles alone $^{51}$ or in conjunction with comparative genomic hybridization. ${ }^{113}$ Although some a priori candidate genes were validated, it was important that many new genes whose expression had not been previously linked to patients surviving gliomas were also identified, and abnormal expression in certain classes of genes predicted survival. For example, best, intermediate, and worst survival times were associated with the abnormal expression of neurogenesis genes, cell proliferation and mitosis genes, and extracellular and extracellular matrix genes, respectively. ${ }^{51}$ Other important findings include the following: 1) loss of chromosome 10 was accompanied by gene expression changes across the genome; and 2) the copy number loss of chromosome 10 and gains of chromosomes 7, 19, and 20 were highly correlated with one another. ${ }^{113}$ These findings, although compelling, are nevertheless preliminary because of the relatively small sample sizes typical of expression array studies. Candidate markers identified in such genome-wide screens, however, represent promising leads for possible validation in larger studies. A recent array study of oligodendroglioma and oligoastrocytoma found that a tumor gain of $8 \mathrm{q}$ may be a negative prognostic factor. ${ }^{87}$

\section{Constitutive Genetic Influences on Prognosis and Survival for Patients With Gliomas}

It is being increasingly demonstrated that common gene polymorphisms influence response to cancer therapies or otherwise influence prognosis and survival (recent reviews on this topic include papers by Loktionov ${ }^{98}$ and Nagasubramanian, et al. $\left.{ }^{109}\right)$. Survival after a diagnosis of glioma has been associated with polymorphisms in EGF, GSTP1, and GSTM1; HLA $A * 32$ and $B * 55$; and GLTSCR1 S397S and ERCC2 D711D. ${ }^{10,117,158,187}$ Because none of these findings has yet been replicated, cautious interpretation is advised. Potentially relevant associations between polymorphisms in genes and treatment response or survival for other cancer sites include the following: IL6 and aggressive breast cancer and ovarian cancer, $A T M$ and radiosensitivity of breast cancer patients, $T G F B 1$ and breast cancer survival, $T N F$ and myeloma relapse, GSTP1 and myeloma outcomes, MDR1 and acute leukemia survival, FGFR4 and soft-tissue sarcoma survival, TYMS and colorectal cancer survival, CDKN2A and bladder cancer survival, and TP53 and lung cancer prognosis. $4,31,37,42,62,67,73,75,108,112,135,143,167,168$ One proposed mechanism is that TP53 variants alter function and the response of tumor cells to chemotherapeutic agents. ${ }^{157}$ The limited studies that have been performed to date have provided several potentially fruitful areas of discovery regarding genetic variation in relation to survival rates for patients with gliomas (for example, signaling pathways for growth factors, cell cycle regulators, modifiers of drug metabolism, and radiotherapy and the immune response).

\section{ENVIRONMENTAL, DEVELOPMENTAL, AND GENETIC RISK FACTORS FOR GLIOMAS}

The only exogenous environmental cause of gliomas that has been unequivocally established is high-dose therapeu- tic radiation; high-dose chemotherapy for other cancers is a strong possibility as well. ${ }^{43,115,183}$ Genetic factors influence risk from these exposures; Relling, et al., ${ }^{132}$ showed that among children treated with cranial radiotherapy and intensive antimetabolite therapy for acute lymphocytic leukemia, those with germline polymorphisms leading to low or absent thiopurine methyltransferase activity were significantly more likely than those without such polymorphisms to develop brain cancer.

Although abundant data obtained in animal and other studies support the biological plausibility of neurocarcinogenecity of endogenous and exogenous chemicals (for example, $N$-nitroso compounds, reactive oxygen and nitrogen species, several industrially used chemicals, and polycyclic aromatic hydrocarbons) to which people are exposed through their essential cellular metabolism, diet, occupation, and personal habits, inconsistent or often null findings from

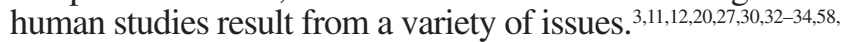
$59,68,71,80,91,95,100,105,111,115,120,124,159,171,183,190$ These include small study sample sizes, chance reporting of false-positive results, imprecise exposure measures (from proxy reporting and exposure history recall issues), inherited or developmental variation in metabolic and repair pathways, unaccounted for protective exposures, differential diffusion of chemicals across the blood-brain barrier, differentially expressed metabolic and repair pathways in the brain, and disease heterogeneity. ${ }^{55,78,115,145,169}$ Progress has been made in understanding environmental contributors to other cancers by joint consideration of inherited variation in detoxification, metabolism, or repair and histological or molecular tumor subtypes, such as TP53 mutations. Two classic examples include the demonstration that specific TP53 mutations in hepatocellular carcinoma occurred exclusively in carriers of variants in epoxide hydrolase and glutathione transferase $\mathrm{mu}^{103}$ and the finding that TP53 mutations in patients with lung cancer were more common in heavy smokers compared with nonsmokers and that homozygous carriers of the glutathione transferase mu deletion were more likely to have transversion mutations in TP53. ${ }^{134}$ More recent examples have shown interactions between a vitamin $\mathrm{D}$ receptor polymorphism and dietary calcium and vitamin D intake in evaluating the risk of colorectal adenoma, ${ }^{18,86}$ interactions of a detoxification gene variation with different environmental exposures in gauging lung cancer risk, ${ }^{72,104,147}$ and different polymorphisms and parental characteristics associated with varying risks of molecularly defined subgroups of childhood leukemia. ${ }^{173,176}$

Because only a small proportion of gliomas are likely to be caused by the effects of inherited rare mutations or highdose radiation, researchers have focused on polymorphisms in genes that might influence susceptibility to brain tumors in concert with environmental exposures.

\section{Polymorphisms in Carcinogen Metabolism and Gliomas}

Glutathione S-transferases and CYPs, as part of the Phase 1 and 2 detoxification process, are involved in the metabolism of many electrophilic compounds, including carcinogens, mutagens, cytotoxic drugs, and metabolites, as well as in the detoxification of products of reactive oxidation. $^{26,47,52,54,122,136,152,153,160,163,188}$ Several case-control studies of the statuses of GSTs and CYPS $1 A 1,2 D 6$, and $1 E 1$ have yielded few positive and replicable associations, ${ }^{41}$, 
$44,84,121,162,178,181$ although the results of some studies indicated specific findings for tumor subtypes (for example, the GSTM1 deletion was more common in GBM cases with the TP53 mutation than in those without (OR 2.8, 95\% CI 0.93-8.4); ${ }^{181}$ the GSTM1 deletion was less common $(\mathrm{p}=$ 0.03 ) and GSTP1 A114V V-carriers were more common than expected $(\mathrm{p}=0.06)$ among oligodendroglioma cases. ${ }^{41}$ The significant multiplicative effects of GSTP1 I105V and CYP2E1 RsaI variants ${ }^{41}$ suggest that gene interactions may be important.

\section{Gliomas and DNA Repair Gene Polymorphisms}

The study of the inherited variation in DNA repair involves another category of genes that have been extensively investigated with respect to cancer because of the importance of DNA repair in maintaining genomic integrity. ${ }^{9,107,179}$ In 2002, Goode and colleagues ${ }^{56}$ reviewed 30 studies reporting on DNA repair polymorphisms in adult gliomas and cancer of the bladder, breast, lung, skin, prostate, head and neck, stomach, and esophagus; the number of studies published has more than quadrupled in the past 3 years. Gliomas and glioma subtypes have been significantly associated with variants in ERCC1, ERCC2, the nearby gene GLTSCR1 (glioma tumor suppressor candidate of unknown function), PRKDC (also known as XRCC7), and MGMT, ${ }^{166,177,180,187}$ but too few studies have been performed to assess consistency. The complexity of the DNA repair pathway is increasingly being revealed, with 130 known genes involved in base excision repair, direct reversal of damage, mismatch repair, nucleotide excision repair, homologous recombination, nonhomologous end joining, sanitization of nucleotide pools, activity of DNA polymerases, editing and processing of nucleases, and postreplicative repair; genes associated with sensitivity to DNA damaging agents; and others suspected of influencing DNA repair functioning are also involved. ${ }^{179}$ Studies focusing on constellations of DNA repair variants involved in these pathways might help elucidate their roles in gliomagenesis and progression.

\section{Gliomas and Polymorphisms in Cell Cycle Regulation}

Dysregulation of the cell cycle (control of proliferation and apoptosis) is a hallmark of most gliomas reviewed by Ichimura, et al., ${ }^{74}$ and MDM2 is a key molecule in maintaining the fidelity of this process. In one study, ${ }^{13}$ the $G$ variant of SNP309 in the MDM2 promoter led to higher expression of $M D M 2$, with concomitant reduced expression of TP53, and was found to be significantly associated with an earlier patient age at tumor development and multiple tumor sites in patients with Li-Fraumeni syndrome, in whom brain tumors are one component.

\section{Infections and Immunological Risk Factors for Gliomas}

Among the most intriguing and consistent findings of the past decade are statistically significant inverse associations between gliomas that develop during adulthood and histories of allergies, chicken pox, and anti-varicella-zostervirus immunoglobulins $\mathrm{G}$ and E. ${ }^{19,138,140,174,175,182,184-186}$ To address lingering doubts that the negative association of gliomas with an allergy history might result from recall issues, Schwartzbaum and colleagues ${ }^{139}$ recently demonstrated that single nucleotide polymorphisms in genes related to asthma are also related to GBM, but in the opposite direction to their association with asthma. To clarify the observed inverse associations of gliomas with asthma, Schwartzbaum, et al., ${ }^{139}$ studied the associations of GBMs with polymorphisms known to be strongly associated with asthma. They examined five single nucleotide polymorphisms in three genes, ILARA, IL13, and ADAM33; ILARA T478C TC, CC and $A 551 G A G, A A$ were significantly positively associated with GBMs (OR 1.64, 95\% CI 1.05-2.55 and OR 1.61, 95\% CI 1.05-2.47, respectively, whereas IL13 C1112T CT, $T T$ was inversely associated with GBMs (OR $0.56,95 \%$ CI $0.33-0.96)$. The polymorphism-GBM associations are in the opposite direction of the polymorphism-asthma associations and because the investigators used germline polymorphisms as biomarkers of the susceptibility to asthma and allergies, the results cannot be attributed to either a recall bias or to the effects of GBMs on the immune system. These findings may validate the association between selfreported allergic conditions and GBMs; however, IL-13 or its shared receptor with IL-4, IL-4RA, may play independent roles in allergic conditions and GBMs. Alternatively, some aspect of allergic conditions themselves may reduce the risk of the development of a GBM or glioma. In either case, these results for allergic conditions and viral infections are consistent with our hypothesis that it is the specific nature of the immune system's response to antigens and not exposure to the antigen per se that is responsible for the inverse associations with gliomas, because there is nearly universal exposure to antigens for both varicella-zostervirus and allergies to pollen, food, and so forth.

Tang and colleagues ${ }^{158}$ demonstrated that GBM is positively associated with human leukocyte antigen genotypes/ haplotypes $B * 13$ and $B * 07-C w^{*} 07(\mathrm{p}=0.01$ and $\mathrm{p}<$ 0.001 , respectively) and is inversely associated with $C w^{*} 01$ $(p=0.05)$. Interestingly, if confirmed, these results may partially explain the higher incidence of GBM in Caucasians because $B * 07$ and $B * 07-C w * 07$ are much more common in Caucasians.

A variety of other viral infections (simian virus 40, JC, $\mathrm{BK}$, other papovaviruses, adenoviruses, retroviruses, the herpesviruses cytomegalovirus and HHV-6, and influenza) and parasitic infections (Toxoplasma gondii) have been investigated in relation to gliomagenesis in experimental studies on animals and in limited epidemiological studies, but conclusions regarding the role (if any) of these infectious agents in human gliomas have remained elusive. ${ }^{2,78,183}$

\section{Genetic Syndromes, Familial Aggregation, Linkage, and Mutagen Sensitivity}

In addition to results from genetic polymorphism studies, evidence suggesting genetic susceptibility to brain cancer comes from studies of genetic syndromes, familial aggregation, linkage, and mutagen sensitivity. Although the handful of genetic syndromes (caused by inherited rare mutations) associated with increased risk of brain tumors (for a review see other studies ${ }^{14,46,74}$ ) account for a small proportion of cases, they provide an important starting point for identifying candidate genes and pathways that could be involved in gliomagenesis. ${ }^{14,46,74}$

Syndromes that include gliomas or medulloblastomas (with gene names and chromosome location) are neurofibromatosis Types 1 and 2 (NF1, 17q11; NF2, 22q12), tuber- 
ous sclerosis (TSC1, 9q34; TSC2, 16p13), retinoblastoma (RB1, 13q14), Li-Fraumeni syndrome (TP53, 17p13), and Turcot syndrome and multiple hamartoma $(A P C, 5 \mathrm{q} 21$; hMLH1, 3p21.3; hMSH2, 2p22-21; PMS2, 7p22; and PTEN, 10q23.3). The roles of more common variants in many of these genes (and related pathways) in sporadic gliomas are unknown. ${ }^{74}$

Demonstration of familial aggregation does not prove a genetic origin, but it is often among the first indicators that genetic susceptibility may play a part in the pathogenesis of a complex disease. Relative risks of brain tumors among family members of patients who harbor them have ranged from 1 to 10; in large, well-conducted studies, familial glioma risks are approximately twofold, similar in magnitude to the familial association involved in breast cancer and other cancers for which susceptibility genes have been identified (for a review see Bondy, et al., ${ }^{14}$ and other studies ${ }^{65,101,182}$ ). The pattern of brain tumor occurrence in families has been attributed to environmental causes in one study ${ }^{57}$ and to multifactorial causes, polygenic causes, and autosomal recessive inheritance in others. ${ }^{14,40,102}$ Paunu, et al., ${ }^{119}$ recently published evidence of a statistically significant linkage to 15q23-q26.3 in 15 Finnish families with multiple cases of glioma (after stringent control for multiple testing, $p=0.03$ ).

Gamma radiation-induced mutagen sensitivity is more commonly found in peripheral lymphocytes in glioma cases than in control cases ${ }^{15,16}$ and it has been suggested that such a mutagen sensitivity is at least partly attributable to inherited variation in capacity to repair radiation damage.

\section{FUTURE STUDIES IN THE MOLECULAR EPIDEMIOLOGY OF GLIOMAS}

Suspected and novel inherited variations in glioma susceptibility and prognosis are likely to be confirmed and identified through multidisciplinary studies involving pathologists, geneticists, epidemiologists, functional genomicists, bioinformaticians, biostatisticians, immunobiologists, and clinicians. These studies will require integration of the following: 1) traditional and molecular pathological analysis involving cytogenetic and epigenetic classifications of tumors to reduce and refine glioma subgroups; 2) new genomic technologies and bioinformatic/biostatistical tools with which to interrogate and explore candidate genes, regions, and pathways and to enhance new discoveries; 3 ) high-quality population resources for causal studies to aid in the selection of cases and controls with well-documented familial and demographic data as well as environmental exposure and personal medical history; and 4) case groups with clearly defined treatment histories for prognostic studies. We hypothesize that demographic, environmental, and immunological factors are likely to influence the susceptibility of patients and disease prognosis, and that different constellations of factors may be involved with different histological and molecular subtypes of glioma.

This brief summary of published case-control studies of polymorphisms involving glioma status and prognosis illustrates several important and widespread problems in current research into the association between genes and diseases, including the paucity of studies assessing consistency for many reported associations, the reporting of falsepositive results, and the lack of consideration of functional

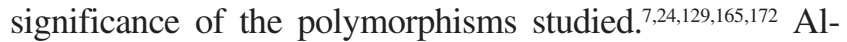
though the most likely explanation of discrepant results among studies is the chance reporting of positive findings in small studies, it is also possible that discrepancies derive from different effects in different populations arising from different exposure and developmental experiences and/or disease heterogeneity. Lack of information on the functional relevance of polymorphisms can also limit reasonable inferences. Future studies will need to include replication or use other means to reduce reporting of false positives.

Different study designs are encouraged because no ideal design is available for the discovery of genetic and environmental associations regarding heterogeneous and relatively rare diseases such as gliomas. Both familial linkage studies and case-control studies may prove helpful in discovering genes associated with glioma susceptibility. For adequate sample sizes and expertise, consortia will be essential for familial linkage studies, studies of gene-environment interactions with even a relatively common glioma subtype such as GBM, and basic epidemiological studies of less common subtypes such as oligodendroglial tumors and other lowgrade glial tumors. The Brain Tumor Epidemiology Consortium (an international group of brain tumor researchers) already has several initiatives in process in these and other areas of brain tumor research. ${ }^{79}$

\section{SUMMARY}

The reasons for variations in glioma incidence according to time of diagnosis, sex, age, ancestry/ethnicity, and geography are poorly understood, as are factors affecting prognosis. There are few established risk factors for gliomas; ionizing radiation and rare mutations in highly penetrant genes associated with certain diseases and syndromes can only be cited to explain relatively few cases. Both familial aggregation of gliomas and the inverse association of allergies and immune-related conditions with gliomas have been shown consistently, but the explanations for these associations are inadequately developed or unknown. Ongoing research on gliomas focuses on classifying homogeneous groups of tumors on the basis of molecular markers and identifying genetic polymorphisms that, in conjunction with developmental experiences and environmental exposures, may increase brain tumor risk. Rather than examine individual genetic polymorphisms in isolation, new research focuses on genetic polymorphisms in pathways involved in carcinogenesis. Related pathways are also studied simultaneously so that confounding by genes with similar functions can be avoided. Large sample sizes are required for such studies, and these large studies will avoid false-positive findings and permit examination of the modifying effects of polymorphisms on environmental exposures, as well as of the potential for interaction between germline mutations and sporadic tumor mutations. Khoury and colleagues ${ }^{85}$ recently argued for the importance of genomic studies of diseases with known strong environmental contributors by stating,

because almost all human diseases result from interactions between genetic variants and the environment, suggesting that genomic research will not contribute to preventing conditions with known environmental risk factors could perpetuate the false competition between nature and nurture.

For diseases such as gliomas, for which most cases have 
yet to be linked to either an environmental or a genetic cause, the greatest potential for discovery may lie in genomic studies in conjunction with continued evaluation of environmental and developmental factors.

Some limited success has been achieved in advancing the treatment of gliomas (as in the case of oligodendrogliomas), but improving the survival rates for patients harboring astrocytic tumors will probably require many randomized clinical trials of novel treatment strategies. In conclusion, most gliomas have extremely poor prognoses and we have limited knowledge of their causes, how to treat them, and other factors that determine prognoses. Thus, there is a great need for large, well-designed epidemiological studies of potential genetic and environmental risk factors and for randomized controlled trials of prognostic factors and treatment strategies for gliomas.

\section{References}

1. Aldape K, Simmons ML, Davis RL, et al: Discrepancies in diagnoses of neuroepithelial neoplasms: the San Francisco Bay Area Adult Glioma Study. Cancer 88:2342-2349, 2000

2. Aldape KD, Okcu MF, Bondy ML, et al: Molecular epidemiology of glioblastoma. Cancer J 9:99-106, 2003

3. Ames BN, Shigenaga MK, Hagen TM: Oxidants, antioxidants, and the degenerative diseases of aging. Proc Natl Acad Sci U S A 90:7915-7922, 1993

4. Angele S, Romestaing P, Moullan N, et al: ATM haplotypes and cellular response to DNA damage: association with breast cancer risk and clinical radiosensitivity. Cancer Res 63:8717-8725, 2003

5. Barker FG II, Chang SM, Larson DA, et al: Age and radiation response in glioblastoma multiforme. Neurosurgery 49: 1288-1298, 2001

6. Barker FG II, Simmons ML, Chang SM, et al: EGFR overexpression and radiation response in glioblastoma multiforme. Int J Radiat Oncol Biol Phys 51:410-418, 2001

7. Begg CB: Reflections on publication criteria for genetic association studies. Cancer Epidemiol Biomarkers Prev 14: 1364-1365, 2005

8. Berleur MP, Cordier S: The role of chemical, physical, or viral exposures and health factors in neurocarcinogenesis: implications for epidemiologic studies of brain tumors. Cancer Causes Control 6:240-256, 1995

9. Berwick M, Vineis P: Markers of DNA repair and susceptibility to cancer in humans: an epidemiologic review. J Natl Cancer Inst 92:874-897, 2000

10. Bhowmick DA, Zhuang Z, Wait SD, et al: A functional polymorphism in the EGF gene is found with increased frequency in glioblastoma multiforme patients and is associated with more aggressive disease. Cancer Res 64:1220-1223, 2004

11. Block G, Patterson B, Subar A: Fruit, vegetables, and cancer prevention: a review of the epidemiological evidence. Nutr Cancer 18:1-29, 1992

12. Boeing H, Schlehofer B, Blettner M, et al: Dietary carcinogens and the risk for glioma and meningioma in Germany. Int $\mathbf{J}$ Cancer 53:561-565, 1993

13. Bond GL, Hu W, Bond EE, et al: A single nucleotide polymorphism in the MDM2 promoter attenuates the p53 tumor suppressor pathway and accelerates tumor formation in humans. Cell 119:591-602, 2004

14. Bondy M, Wiencke J, Wrensch M, et al: Genetics of primary brain tumors: a review. J Neurooncol 18:69-81, 1994

15. Bondy ML, Kyritsis AP, Gu J, et al: Mutagen sensitivity and risk of gliomas: a case-control analysis. Cancer Res 56:1484-1486, 1996

16. Bondy ML, Wang LE, El-Zein R, et al: Gamma-radiation sen- sitivity and risk of glioma. J Natl Cancer Inst 93:1553-1557, 2001

17. Boon K, Edwards JB, Siu IM, et al: Comparison of medulloblastoma and normal neural transcriptomes identifies a restricted set of activated genes. Oncogene 22:7687-7694, 2003

18. Boyapati SM, Bostick RM, McGlynn KA, et al: Calcium, vitamin D, and risk for colorectal adenoma: dependency on vitamin D receptor BsmI polymorphism and nonsteroidal anti-inflammatory drug use? Cancer Epidemiol Biomarkers Prev 12: 631-637, 2003

19. Brenner AV, Linet MS, Fine HA, et al: History of allergies and autoimmune diseases and risk of brain tumors in adults. Int $\mathbf{J}$ Cancer 99:252-259, 2002

20. Burch JD, Craib KJ, Choi BC, et al: An exploratory case-control study of brain tumors in adults. J Natl Cancer Inst 78:601-609, 1987

21. Burnet NG, Jefferies SJ, Benson RJ, et al: Years of life lost (YLL) from cancer is an important measure of population burden-and should be considered when allocating research funds. Br J Cancer 92:241-245, 2005

22. Burton EC, Lamborn KR, Feuerstein BG, et al: Genetic aberrations defined by comparative genomic hybridization distinguish long-term from typical survivors of glioblastoma. Cancer Res 62:6205-6210, 2002

23. Burton EC, Lamborn KR, Forsyth P, et al: Aberrant p53, mdm2, and proliferation differ in glioblastomas from long-term compared with typical survivors. Clin Cancer Res 8:180-187, 2002

24. Byrnes G, Gurrin L, Dowty J, et al: Publication policy or publication bias? Cancer Epidemiol Biomarkers Prev 14:1363, 2005

25. Cairncross JG, Ueki K, Zlatescu MC, et al: Specific genetic predictors of chemotherapeutic response and survival in patients with anaplastic oligodendrogliomas. J Natl Cancer Inst 90: 1473-1479, 1998

26. Caporaso N, Landi MT, Vineis P: Relevance of metabolic polymorphisms to human carcinogenesis: evaluation of epidemiologic evidence. Pharmacogenetics 1:4-19, 1991

27. Carozza SE, Wrensch M, Miike R, et al: Occupation and adult gliomas. Am J Epidemiol 152:838-846, 2000

28. CBTRUS: Statistical Report: Primary Brain Tumors in the United States, 1995-1999. (http://www.cbtrus.org/reports// 2002/2002report.pdf) [Accessed 19 October 2005]

29. CBTRUS: Statistical Report: Primary Brain Tumors in the United States, 1997-2001. (http://www.cbtrus.org/reports// 2004-2005/2005report.pdf) [Accessed 19 October 2005]

30. Chen H, Ward MH, Tucker KL, et al: Diet and risk of adult glioma in eastern Nebraska, United States. Cancer Causes Control 13:647-655, 2002

31. Chen J, Hunter DJ, Stampfer MJ, et al: Polymorphism in the thymidylate synthase promoter enhancer region modifies the risk and survival of colorectal cancer. Cancer Epidemiol Biomarkers Prev 12:958-962, 2003

32. Cobbs CS, Whisenhunt TR, Wesemann DR, et al: Inactivation of wild-type p53 protein function by reactive oxygen and nitrogen species in malignant glioma cells. Cancer Res 63:8670-8673, 2003

33. Cocco P, Dosemeci M, Heineman EF: Brain cancer and occupational exposure to lead. J Occup Environ Med 40:937-942, 1998

34. Cocco P, Heineman EF, Dosemeci M: Occupational risk factors for cancer of the central nervous system (CNS) among US women. Am J Ind Med 36:70-74, 1999

35. Coons SW, Johnson PC, Scheithauer BW, et al: Improving diagnostic accuracy and interobserver concordance in the classification and grading of primary gliomas. Cancer 79:1381-1393, 1997

36. Curran WJ Jr, Scott CB, Horton J, et al: Recursive partitioning analysis of prognostic factors in three Radiation Therapy Oncology Group malignant glioma trials. J Natl Cancer Inst 85: 704-710, 1993 
37. Dasgupta RK, Adamson PJ, Davies FE, et al: Polymorphic variation in GSTP1 modulates outcome following therapy for multiple myeloma. Blood 102:2345-2350, 2003

38. Davis FG, Freels S, Grutsch J, et al: Survival rates in patients with primary malignant brain tumors stratified by patient age and tumor histological type: an analysis based on Surveillance, Epidemiology, and End Results (SEER) data, 1973-1991. J Neurosurg 88:1-10, 1998

39. Davis FG, McCarthy B, Jukich P: The descriptive epidemiology of brain tumors. Neuroimaging Clin N Am 9:581-594, 1999

40. de Andrade M, Barnholtz JS, Amos CI, et al: Segregation analysis of cancer in families of glioma patients. Genet Epidemiol 20:258-270, 2001

41. De Roos AJ, Rothman N, Inskip PD, et al: Genetic polymorphisms in GSTM1, -P1, -T1, and CYP2E1 and the risk of adult brain tumors. Cancer Epidemiol Biomarkers Prev 12:14-22, 2003

42. DeMichele A, Martin AM, Mick R, et al: Interleukin-6 $-174 \mathrm{G} \rightarrow \mathrm{C}$ polymorphism is associated with improved outcome in high-risk breast cancer. Cancer Res 63:8051-8056, 2003

43. Edick MJ, Cheng C, Yang W, et al: Lymphoid gene expression as a predictor of risk of secondary brain tumors. Genes Chromosomes Cancer 42:107-116, 2005

44. Elexpuru-Camiruaga J, Buxton N, Kandula V, et al: Susceptibility to astrocytoma and meningioma: influence of allelism at glutathione S-transferase (GSTT1 and GSTM1) and cytochrome P450 (CYP2D6) loci. Cancer Res 55:4237-4239, 1995

45. Eley GD, Reiter JL, Pandita A, et al: A chromosomal region 7p11.2 transcript map: its development and application to the study of EGFR amplicons in glioblastoma. Neuro-oncol 4: 86-94, 2002

46. El-Zein R, Minn AY, Wrensch M, et al: Epidemiology of brain tumors, in Levin VA (ed): Cancer in the Nervous System, ed 2. New York: Oxford University Press, 2002, pp 252-266

47. Evans WE, Relling MV: Pharmacogenomics: translating functional genomics into rational therapeutics. Science 286:487-491, 1999

48. Feldkamp MM, Lala P, Lau N, et al: Expression of activated epidermal growth factor receptors, Ras-guanosine triphosphate, and mitogen-activated protein kinase in human glioblastoma multiforme specimens. Neurosurgery 45:1442-1453, 1999

49. Felsberg J, Erkwoh A, Sabel MC, et al: Oligodendroglial tumors: refinement of candidate regions on chromosome arm $1 \mathrm{p}$ and correlation of $1 \mathrm{p} / 19 \mathrm{q}$ status with survival. Brain Pathol 14:121-130, 2004

50. Fortin D, Cairncross GJ, Hammond RR: Oligodendroglioma: an appraisal of recent data pertaining to diagnosis and treatment. Neurosurgery 45:1279-1291, 1999

51. Freije WA, Castro-Vargas FE, Fang Z, et al: Gene expression profiling of gliomas strongly predicts survival. Cancer Res 64: 6503-6510, 2004

52. Friedberg T: Cytochrome P450 polymorphisms as risk factors for steroid hormone-related cancers. Am J Pharmacogenomics 1:83-91, 2001

53. Fukuda ME, Iwadate $\mathrm{Y}$, Machida $\mathrm{T}$, et al: Cathepsin $\mathrm{D}$ is a potential serum marker for poor prognosis in glioma patients. Cancer Res 65:5190-5194, 2005

54. Garte S, Gaspari L, Alexandrie AK, et al: Metabolic gene polymorphism frequencies in control populations. Cancer Epidemiol Biomarkers Prev 10:1239-1248, 2001

55. Gobbel GT, Bellinzona M, Vogt AR, et al: Response of postmitotic neurons to $\mathrm{X}$-irradiation: implications for the role of DNA damage in neuronal apoptosis. J Neurosci 18:147-155, 1998

56. Goode EL, Ulrich CM, Potter JD: Polymorphisms in DNA repair genes and associations with cancer risk. Cancer Epidemiol Biomarkers Prev 11:1513-1530, 2002

57. Grossman SA, Osman M, Hruban R, et al: Central nervous system cancers in first-degree relatives and spouses. Cancer Invest 17:299-308, 1999

58. Guo WD, Linet MS, Chow WH, et al: Diet and serum markers in relation to primary brain tumor risk in China. Nutr Cancer 22:143-150, 1994

59. Gurney JG, Chen M, Skluzacek MC, et al: Null association between frequency of cured meat consumption and methylvaline and ethylvaline hemoglobin adduct levels: the $\mathrm{N}$-nitroso brain cancer hypothesis. Cancer Epidemiol Biomarkers Prev 11:421-422, 2002

60. Hartmann C, Johnk L, Kitange G, et al: Transcript map of the 3.7$\mathrm{Mb}$ D19S112-D19S246 candidate tumor suppressor region on the long arm of chromosome 19. Cancer Res 62:4100-4108, 2002

61. Hashimoto N, Murakami M, Takahashi Y, et al: Correlation between genetic alteration and long-term clinical outcome of patients with oligodendroglial tumors, with identification of a consistent region of deletion on chromosome arm 1p. Cancer 97:2254-2261, 2003

62. Hefler LA, Grimm C, Ackermann S, et al: An interleukin-6 gene promoter polymorphism influences the biological phenotype of ovarian cancer. Cancer Res 63:3066-3068, 2003

63. Hegi ME, Diserens AC, Gorlia T, et al: MGMT gene silencing and benefit from temozolomide in glioblastoma. N Engl J Med 352:997-1003, 2005

64. Heimberger AB, Hlatky R, Suki D, et al: Prognostic effect of epidermal growth factor receptor and EGFRvIII in glioblastoma multiforme patients. Clin Cancer Res 11:1462-1466, 2005

65. Hemminki K, Li X, Vaittinen P, et al: Cancers in the first-degree relatives of children with brain tumours. Br J Cancer 83:407-411, 2000

66. Horn B, Heideman R, Geyer R, et al: A multi-institutional retrospective study of intracranial ependymoma in children: identification of risk factors. J Pediatr Hematol Oncol 21:203-211, 1999

67. Hsia TC, Chiang HC, Chiang D, et al: Prediction of survival in surgical unresectable lung cancer by artificial neural networks including genetic polymorphisms and clinical parameters. J Clin Lab Anal 17:229-234, 2003

68. Hu J, La Vecchia C, Negri E, et al: Diet and brain cancer in adults: a case-control study in northeast China. Int J Cancer 81:20-23, 1999

69. Huang B, Starostik P, Kuhl J, et al: Loss of heterozygosity on chromosome 22 in human ependymomas. Acta Neuropathol (Berl) 103:415-420, 2002

70. Huang H, Okamoto Y, Yokoo H, et al: Gene expression profiling and subgroup identification of oligodendrogliomas. Oncogene 23:6012-6022, 2004

71. Huncharek M, Kupelnick B, Wheeler L: Dietary cured meat and the risk of adult glioma: a meta-analysis of nine observational studies. J Environ Pathol Toxicol Oncol 22:129-137, 2003

72. Hung RJ, Boffetta P, Brockmoller J, et al: CYP1A1 and GSTM1 genetic polymorphisms and lung cancer risk in Caucasian nonsmokers: a pooled analysis. Carcinogenesis 24:875-882, 2003

73. Iacopetta B, Grieu F, Joseph D: The -174 G/C gene polymorphism in interleukin-6 is associated with an aggressive breast cancer phenotype. Br J Cancer 90:419-422, 2004

74. Ichimura K, Ohgaki H, Kleihues P, et al: Molecular pathogenesis of astrocytic tumours. J Neurooncol 70:137-160, 2004

75. Illmer T, Schuler US, Thiede C, et al: MDR1 gene polymorphisms affect therapy outcome in acute myeloid leukemia patients. Cancer Res 62:4955-4962, 2002

76. Ino Y, Betensky RA, Zlatescu MC, et al: Molecular subtypes of anaplastic oligodendroglioma: implications for patient management at diagnosis. Clin Cancer Res 7:839-845, 2001

77. Ino Y, Silver JS, Blazejewski L, et al: Common regions of deletion on chromosome 22q12.3-q13.1 and 22q13.2 in human astrocytomas appear related to malignancy grade. J Neuropathol Exp Neurol 58:881-885, 1999

78. Inskip PD, Linet MS, Heineman EF: Etiology of brain tumors in adults. Epidemiol Rev 17:382-414, 1995

79. Ioannidis JP, Bernstein J, Boffetta P, et al: A network of investigator networks in human genome epidemiology. Am J Epidemiol 162:302-304, 2005 
80. Ito N, Hirose M: Antioxidants-carcinogenic and chemopreventive properties. Adv Cancer Res 53:247-302, 1989

81. James CD, Smith JS, Jenkins RB: Genetic and molecular basis of primary central nervous system tumors, in Levin VA (ed): Cancer in the Nervous System, ed 2. New York: Oxford University Press, 2002, pp 239-251

82. James D: Genetic Aspects, in Bernstein M, Berger M (eds): Neuro-Oncology: The Essentials. New York: Thieme Medical Publishers, 2000, pp 42-48

83. Karak AK, Singh R, Tandon PN, et al: A comparative survival evaluation and assessment of interclassification concordance in adult supratentorial astrocytic tumors. Pathol Oncol Res 6: 46-52, 2000

84. Kelsey KT, Wrensch M, Zuo ZF, et al: A population-based casecontrol study of the CYP2D6 and GSTT1 polymorphisms and malignant brain tumors. Pharmacogenetics 7:463-468, 1997

85. Khoury MJ, Davis R, Gwinn M, et al: Do we need genomic research for the prevention of common diseases with environmental causes? Am J Epidemiol 161:799-805, 2005

86. Kim HS, Newcomb PA, Ulrich CM, et al: Vitamin D receptor polymorphism and the risk of colorectal adenomas: evidence of interaction with dietary vitamin D and calcium. Cancer Epidemiol Biomarkers Prev 10:869-874, 2001

87. Kitange G, Misra A, Law M, et al: Chromosomal imbalances detected by array comparative genomic hybridization in human oligodendrogliomas and mixed oligoastrocytomas. Genes Chromosomes Cancer 42:68-77, 2005

88. Kleihues P, Cavenee WK: Tumors of the Central Nervous System: Pathology and Genetics. Lyon, France: International Agency for Research on Cancer, 1997

89. Kleihues P, Ohgaki H: Phenotype vs genotype in the evolution of astrocytic brain tumors. Toxicol Pathol 28:164-170, 2000

90. Kleihues P, Schauble B, zur Hausen A, et al: Tumors associated with p53 germline mutations: a synopsis of 91 families. Am J Pathol 150:1-13, 1997

91. Krishnan G, Felini M, Carozza SE, et al: Occupation and adult gliomas in the San Francisco Bay Area. J Occup Environ Med 45:639-647, 2003

92. Kyritsis AP, Bondy ML, Hess KR, et al: Prognostic significance of p53 immunoreactivity in patients with glioma. Clin Cancer Res 1:1617-1622, 1995

93. Lamborn KR, Chang SM, Prados MD: Prognostic factors for survival of patients with glioblastoma: recursive partitioning analysis. Neuro-oncol 6:227-235, 2004

94. Lang FF, Miller DC, Koslow M, et al: Pathways leading to glioblastoma multiforme: a molecular analysis of genetic alterations in 65 astrocytic tumors. J Neurosurg 81:427-436, 1994

95. Lee M, Wrensch M, Miike R: Dietary and tobacco risk factors for adult onset glioma in the San Francisco Bay Area (California, USA). Cancer Causes Control 8:13-24, 1997

96. Levin V, Liebel S, Gutin P: Neoplasms of the central nervous system (section 2), in DeVita VTJ, Hellman S, Rosenberg SA (eds): Cancer: Principles and Practice of Oncology, ed 6. Philadelphia: Lippincott Williams \& Wilkins, 2001, Vol 2, pp 2100-2160

97. Lin H, Bondy ML, Langford LA, et al: Allelic deletion analyses of MMAC/PTEN and DMBT1 loci in gliomas: relationship to prognostic significance. Clin Cancer Res 4:2447-2454, 1998

98. Loktionov A: Common gene polymorphisms, cancer progression and prognosis. Cancer Lett 208:1-33, 2004

99. Louis DN, Stemmer-Rachamimov AO: Pathology and classification, in Bernstein M, Berger M (eds): Neuro-Oncology: The Essentials. New York: Thieme Medical Publishers, 2000, pp $18-29$

100. Maekawa A, Mitsumori K: Spontaneous occurrence and chemical induction of neurogenic tumors in rats-influence of host factors and specificity of chemical structure. Crit Rev Toxicol 20:287-310, 1990

101. Malmer B, Grönberg H, Bergenheim AT, et al: Familial aggre- gation of astrocytoma in northern Sweden: an epidemiological cohort study. Int J Cancer 81:366-370, 1999

102. Malmer B, Iselius L, Holmberg E, et al: Genetic epidemiology of glioma. Br J Cancer 84:429-434, 2001

103. McGlynn KA, Rosvold EA, Lustbader ED, et al: Susceptibility to hepatocellular carcinoma is associated with genetic variation in the enzymatic detoxification of aflatoxin B1. Proc Natl Acad Sci U S A 92:2384-2387, 1995

104. Miller DP, De Vivo I, Neuberg D, et al: Association between self-reported environmental tobacco smoke exposure and lung cancer: modification by GSTP1 polymorphism. Int J Cancer 104:758-763, 2003

105. Mills PK, Preston-Martin S, Annegers JF, et al: Risk factors for tumors of the brain and cranial meninges in Seventh-Day Adventists. Neuroepidemiology 8:266-275, 1989

106. Mochizuki S, Iwadate Y, Namba H, et al: Homozygous deletion of the p16/MTS-1/CDKN2 gene in malignant gliomas is infrequent among Japanese patients. Int J Oncol 15:983-989, 1999

107. Mohrenweiser HW, Wilson DM III, Jones IM: Challenges and complexities in estimating both the functional impact and the disease risk associated with the extensive genetic variation in human DNA repair genes. Mutat Res 526:93-125, 2003

108. Morimoto Y, Ozaki T, Ouchida M, et al: Single nucleotide polymorphism in fibroblast growth factor receptor 4 at codon 388 is associated with prognosis in high-grade soft tissue sarcoma. Cancer 98:2245-2250, 2003

109. Nagasubramanian R, Innocenti F, Ratain MJ: Pharmacogenetics in cancer treatment. Annu Rev Med 54:437-452, 2003

110. National Center for Biotechnology Information: Entrez Gene. (http://www.ncbi.nlm.nih.gov/entrez/query.fcgi?CMD=search $\& D B=$ gene) [Accessed 11 November 2005]

111. Navas-Acien A, Pollan M, Gustavsson P, et al: Occupation, exposure to chemicals and risk of gliomas and meningiomas in Sweden. Am J Ind Med 42:214-227, 2002

112. Neben K, Mytilineos J, Moehler TM, et al: Polymorphisms of the tumor necrosis factor- $\alpha$ gene promoter predict for outcome after thalidomide therapy in relapsed and refractory multiple myeloma. Blood 100:2263-2265, 2002

113. Nigro JM, Misra A, Zhang L, et al: Integrated array-comparative genomic hybridization and expression array profiles identify clinically relevant molecular subtypes of glioblastoma. Cancer Res 65:1678-1686, 2005

114. Ohgaki H, Dessen P, Jourde B, et al: Genetic pathways to glioblastoma: a population-based study. Cancer Res 64: 6892-6899, 2004

115. Ohgaki H, Kleihues P: Epidemiology and etiology of gliomas. Acta Neuropathol (Berl) 109:93-108, 2005

116. Okada Y, Hurwitz EE, Esposito JM, et al: Selection pressures of TP53 mutation and microenvironmental location influence Epidermal Growth Factor Receptor gene amplification in human glioblastomas. Cancer Res 63:413-416, 2003

117. Okcu MF, Selvan M, Wang LE, et al: Glutathione $S$-transferase polymorphisms and survival in primary malignant glioma. Clin Cancer Res 10:2618-2625, 2004

118. Oskam NT, Bijleveld EH, Hulsebos TJ: A region of common deletion in 22q13.3 in human glioma associated with astrocytoma progression. Int J Cancer 85:336-339, 2000

119. Paunu N, Lahermo P, Onkamo P, et al: A novel low-penetrance locus for familial glioma at $15 \mathrm{q} 23-\mathrm{q} 26.3$. Cancer Res 62:3798-3802, 2002

120. Peterson DL, Sheridan PJ, Brown WE Jr: Animal models for brain tumors: historical perspectives and future directions. J Neurosurg 80:865-876, 1994

121. Pinarbasi H, Silig Y, Gurelik M: Genetic polymorphisms of GSTs and their association with primary brain tumor incidence. Cancer Genet Cytogenet 156:144-149, 2005

122. Poulsen HE, Loft S, Wassermann K: Cancer risk related to genetic polymorphisms in carcinogen metabolism and DNA repair. Pharmacol Toxicol 72 (Suppl 1):93-103, 1993 
123. Preston-Martin S, Mack WJ: Neoplasms of the nervous system, in Schottenfeld D, Fraumeni JF Jr (eds): Cancer Epidemiology and Prevention, ed 2. New York: Oxford University Press, 1996, pp 1231-1281

124. Preston-Martin S, Pogoda JM, Mueller BA, et al: Maternal consumption of cured meats and vitamins in relation to pediatric brain tumors. Cancer Epidemiol Biomarkers Prev 5: 599-605, 1996

125. Puduvalli VK, Kyritsis AP, Hess KR, et al: Patterns of expression of $\mathrm{Rb}$ and p16 in astrocytic gliomas, and correlation with survival. Int J Oncol 17:963-969, 2000

126. Rasheed BK, McLendon RE, Friedman HS, et al: Chromosome 10 deletion mapping in human gliomas: a common deletion region in 10q25. Oncogene 10:2243-2246, 1995

127. Rasheed BK, McLendon RE, Herndon JE, et al: Alterations of the TP53 gene in human gliomas. Cancer Res 54:1324-1330, 1994

128. Rasheed BK, Wiltshire RN, Bigner SH, et al: Molecular pathogenesis of malignant gliomas. Curr Opin Oncol 11:162-167, 1999

129. Rebbeck TR, Martinez ME, Sellers TA, et al: Genetic variation and cancer: improving the environment for publication of association studies. Cancer Epidemiol Biomarkers Prev 13:1985-1986, 2004

130. Reifenberger G, Ichimura K, Reifenberger J, et al: Refined mapping of 12q13-q15 amplicons in human malignant gliomas suggests CDK4/SAS and MDM2 as independent amplification targets. Cancer Res 56:5141-5145, 1996

131. Reifenberger G, Reifenberger J, Ichimura K, et al: Amplification at 12q13-14 in human malignant gliomas is frequently accompanied by loss of heterozygosity at loci proximal and distal to the amplification site. Cancer Res 55:731-734, 1995

132. Relling MV, Rubnitz JE, Rivera GK, et al: High incidence of secondary brain tumors after radiotherapy and antimetabolites. Lancet 354:34-39, 1999

133. Riemenschneider MJ, Knobbe CB, Reifenberger G: Refined mapping of 1q32 amplicons in malignant gliomas confirms MDM4 as the main amplification target. Int $\mathbf{J}$ Cancer 104: 752-757, 2003

134. Ryberg D, Kure E, Lystad S, et al: p53 mutations in lung tumors: relationship to putative susceptibility markers for cancer. Cancer Res 54:1551-1555, 1994

135. Sakano S, Berggren P, Kumar R, et al: Clinical course of bladder neoplasms and single nucleotide polymorphisms in the CDKN2A gene. Int J Cancer 104:98-103, 2003

136. Salinas AE, Wong MG: Glutathione $S$-transferases-a review. Curr Med Chem 6:279-309, 1999

137. Sano T, Lin H, Chen $X$, et al: Differential expression of $M M A C / P T E N$ in glioblastoma multiforme: relationship to localization and prognosis. Cancer Res 59:1820-1824, 1999

138. Schlehofer B, Blettner M, Preston-Martin S, et al: Role of medical history in brain tumor development. Results from the international adult brain tumor study. Int J Cancer 82:155-160, 1999

139. Schwartzbaum J, Ahlbom A, Malmer B, et al: Polymorphisms associated with asthma are inversely related to glioblastoma multiforme. Cancer Res 65:6459-6465, 2005

140. Schwartzbaum J, Jonsson F, Ahlbom A, et al: Cohort studies of association between self-reported allergic conditions, immune-related diagnoses and glioma and meningioma risk. Int J Cancer 106:423-428, 2003

141. Scott CB, Scarantino C, Urtasun R, et al: Validation and predictive power of Radiation Therapy Oncology Group (RTOG) recursive partitioning analysis classes for malignant glioma patients: a report using RTOG 90-06. Int J Radiat Oncol Biol Phys 40:51-55, 1998

142. Scott JN, Rewcastle NB, Brasher PM, et al: Long-term glioblastoma multiforme survivors: a population-based study. Can J Neurol Sci 25:197-201, 1998
143. Shu XO, Gao YT, Cai Q, et al: Genetic polymorphisms in the $T G F-\beta 1$ gene and breast cancer survival: a report from the Shanghai Breast Cancer Study. Cancer Res 64:836-839, 2004

144. Sigurdson AJ, Bondy ML, Hess KR, et al: Gamma-ray mutagen sensitivity and survival in patients with glioma. Clin Cancer Res 4:3031-3035, 1998

145. Silasi G, Diaz-Heijtz R, Besplug J, et al: Selective brain responses to acute and chronic low-dose X-ray irradiation in males and females. Biochem Biophys Res Commun 325: 1223-1235, 2004

146. Simmons ML, Lamborn KR, Takahashi M, et al: Analysis of complex relationships between age, p53, epidermal growth factor receptor, and survival in glioblastoma patients. Cancer Res 61:1122-1128, 2001

147. Skuladottir H, Autrup H, Autrup J, et al: Polymorphisms in genes involved in xenobiotic metabolism and lung cancer risk under the age of 60 years. A pooled study of lung cancer patients in Denmark and Norway. Lung Cancer 48:187-199, 2005

148. Smith JS, Alderete B, Minn Y, et al: Localization of common deletion regions on $1 \mathrm{p}$ and $19 \mathrm{q}$ in human gliomas and their association with histological subtype. Oncogene 18:4144-4152, 1999

149. Smith JS, Perry A, Borell TJ, et al: Alterations of chromosome arms $1 \mathrm{p}$ and $19 \mathrm{q}$ as predictors of survival in oligodendrogliomas, astrocytomas, and mixed oligoastrocytomas. J Clin Oncol 18:636-645, 2000

150. Smith JS, Tachibana I, Passe SM, et al: PTEN mutation, EGFR amplification, and outcome in patients with anaplastic astrocytoma and glioblastoma multiforme. J Natl Cancer Inst 93:1246-1256, 2001

151. Smith JS, Tachibana I, Pohl U, et al: A transcript map of the chromosome 19q-arm glioma tumor suppressor region. Genomics 64:44-50, 2000

152. Strange RC, Fryer AA: The glutathione $S$-transferases: influence of polymorphism on cancer susceptibility. IARC Sci Pub 148:231-249, 1999

153. Strange RC, Lear JT, Fryer AA: Polymorphism in glutathione $S$-transferase loci as a risk factor for common cancers. Arch Toxicol Suppl 20:419-428, 1998

154. Stupp R, Mason WP, van den Bent MJ, et al: Radiotherapy plus concomitant and adjuvant temozolomide for glioblastoma. N Engl J Med 352:987-996, 2005

155. Su WT, Alaminos M, Mora J, et al: Positional gene expression analysis identifies $12 \mathrm{q}$ overexpression and amplification in a subset of neuroblastomas. Cancer Genet Cytogenet 154:131-137, 2004

156. Suarez-Merino B, Hubank M, Revesz T, et al: Microarray analysis of pediatric ependymoma identifies a cluster of 112 candidate genes including four transcripts at 22q12.1-q13.3. Neuro-oncol 7:20-31, 2005

157. Sullivan A, Syed N, Gasco M, et al: Polymorphism in wildtype p53 modulates response to chemotherapy in vitro and in vivo. Oncogene 23:3328-3337, 2004

158. Tang J, Shao W, Dorak MT, et al: Positive and negative associations of human leukocyte antigen variants with the onset and prognosis of adult glioblastoma multiforme. Cancer Epidemiol Biomarkers Prev 14:2040-2044, 2005

159. Tedeschi-Blok N, Schwartzbaum J, Lee M, et al: Dietary calcium consumption and astrocytic glioma: the San Francisco Bay Area Adult Glioma Study, 1991-1995. Nutr Cancer 39: 196-203, 2001

160. Thier R, Bruning T, Roos PH, et al: Markers of genetic susceptibility in human environmental hygiene and toxicology: the role of selected CYP, NAT and GST genes. Int J Hyg Environ Health 206:149-171, 2003

161. Thiessen B, Maguire JA, McNeil K, et al: Loss of heterozygosity for loci on chromosome arms $1 \mathrm{p}$ and 10q in oligodendroglial tumors: relationship to outcome and chemosensitivity. J Neurooncol 64:271-278, 2003 
162. Trizna Z, de Andrade M, Kyritsis AP, et al: Genetic polymorphisms in glutathione $S$-transferase $\mu$ and $\theta, N$-acetyltransferase, and $C Y P 1 A 1$ and risk of gliomas. Cancer Epidemiol Biomarkers Prev 7:553-555, 1998

163. Tsigelny IF, Kotlovyi V, Wasserman L: SNP analysis combined with protein structure prediction defines structure-functional relationships in cancer related cytochrome P450 estrogen metabolism. Curr Med Chem 11:525-538, 2004

164. von Deimling A, Louis DN, Wiestler OD: Molecular pathways in the formation of gliomas. Glia 15:328-338, 1995

165. Wacholder S, Chanock S, Garcia-Closas M, et al: Assessing the probability that a positive report is false: an approach for molecular epidemiology studies. J Natl Cancer Inst 96: 434-442, 2004

166. Wang LE, Bondy ML, Shen H, et al: Polymorphisms of DNA repair genes and risk of glioma. Cancer Res 64:5560-5563, 2004

167. Wang YC, Chen CY, Chen SK, et al: $p 53$ codon 72 polymorphism in Taiwanese lung cancer patients: association with lung cancer susceptibility and prognosis. Clin Cancer Res 5: 129-134, 1999

168. Wang YC, Lee HS, Chen SK, et al: Prognostic significance of p53 codon 72 polymorphism in lung carcinomas. Eur J Cancer 35:226-230, 1999

169. Watts LT, Rathinam ML, Schenker S, et al: Astrocytes protect neurons from ethanol-induced oxidative stress and apoptotic death. J Neurosci Res 80:655-666, 2005

170. Wei Q, Bondy ML, Mao L, et al: Reduced expression of mismatch repair genes measured by multiplex reverse transcription-polymerase chain reaction in human gliomas. Cancer Res 57:1673-1677, 1997

171. Wesseling C, Pukkala E, Neuvonen K, et al: Cancer of the brain and nervous system and occupational exposures in Finnish women. J Occup Environ Med 44:663-668, 2002

172. Whittemore AS: Genetic association studies: time for a new paradigm? Cancer Epidemiol Biomarkers Prev 14:1359-1360, 2005

173. Wiemels JL, Smith RN, Taylor GM, et al: Methylenetetrahydrofolate reductase (MTHFR) polymorphisms and risk of molecularly defined subtypes of childhood acute leukemia. Proc Natl Acad Sci U S A 98:4004-4009, 2001

174. Wiemels JL, Wiencke JK, Patoka J, et al: Reduced immunoglobulin E and allergy among adults with glioma compared with controls. Cancer Res 64:8468-8473, 2004

175. Wiemels JL, Wiencke JK, Sison JD, et al: History of allergies among adults with glioma and controls. Int J Cancer 98: 609-615, 2002

176. Wiemels JL, Zhang Y, Chang J, et al: RAS mutation is associated with hyperdiploidy and parental characteristics in pediatric acute lymphoblastic leukemia. Leukemia 19:415-419, 2005

177. Wiencke J, Aldalpe K, McMillan A, et al: Molecular features of adult glioma associated with patient race/ethnicity, age, and a polymorphism in $O^{6}$-methylguanine-DNA-methyltransferase. Cancer Epidemiol Biomarkers Prev 14:1774-1783, 2005

178. Wiencke JK, Wrensch MR, Miike R, et al: Population-based study of glutathione $S$-transferase mu gene deletion in adult glioma cases and controls. Carcinogenesis 18:1431-1433, 1997
179. Wood RD, Mitchell M, Sgouros J, et al: Human DNA repair genes. Science 291: 1284-1289, 2001

180. Wrensch M, Kelsey K, Liu M, et al: ERCC1 and ERCC2 polymorphisms and adult glioma. Neuro-oncol 7:495-507, 2005

181. Wrensch M, Kelsey KT, Liu M, et al: Glutathione-S-transferase variants and adult glioma. Cancer Epidemiol Biomarkers Prev 13:461-467, 2004

182. Wrensch M, Lee M, Miike R, et al: Familial and personal medical history of cancer and nervous system conditions among adults with glioma and controls. Am J Epidemiol 145:581-593, 1997

183. Wrensch M, Minn Y, Chew T, et al: Epidemiology of primary brain tumors: current concepts and review of the literature. Neuro-oncol 4:278-299, 2002

184. Wrensch M, Weinberg A, Wiencke J, et al: Does prior infection with varicella-zoster virus influence risk of adult glioma? Am J Epidemiol 145:594-597, 1997

185. Wrensch M, Weinberg A, Wiencke J, et al: Prevalence of antibodies to four herpesviruses among adults with glioma and controls. Am J Epidemiol 154:161-165, 2001

186. Wrensch M, Weinberg A, Wiencke J, et al: History of chickenpox and shingles and prevalence of antibodies to varicellazoster virus and three other herpesviruses among adults with glioma and controls. Am J Epidemiol 161:929-938, 2005

187. Yang P, Kollmeyer TM, Buckner K, et al: Polymorphisms in GLTSCR1 and ERCC2 are associated with the development of oligodendrogliomas. Cancer 103:2363-2372, 2005

188. Yuspa SH, Shields PG: Etiology of cancer: chemical factors, in De Vita J, Hellman VTS (eds): Cancer: Principles and Practice of Oncology. Philadelphia: Lippincott Williams \& Wilkins, 2001, pp 179-193

189. Zheng PP, Hop WC, Sillevis Smitt PA, et al: Low-molecular weight caldesmon as a potential serum marker for glioma. Clin Cancer Res 11:4388-4392, 2005

190. Zheng T, Cantor KP, Zhang Y, et al: Occupational risk factors for brain cancer: a population-based case-control study in Iowa. J Occup Environ Med 43:317-324, 2001

191. Zhu A, Shaeffer J, Leslie S, et al: Epidermal growth factor receptor: an independent predictor of survival in astrocytic tumors given definitive irradiation. Int J Radiat Oncol Biol Phys 34:809-815, 1996

Manuscript received September 15, 2005.

Accepted in final form October 18, 2005.

This work was supported by the following grants from the National Cancer Institute: No. R01CA52689 (Margaret Wrensch, Principal Investigator), No. P50CA097257 (Mitchel Berger, Principal Investigator), and No. R03CA103379 (Judith Schwartzbaum, Principal Investigator).

Address reprint requests to: Margaret Wrensch, Ph.D., Department of Neurological Surgery, 44 Page Street, Suite 503, University of California, San Francisco, California 94102. email: wrensch@itsa. ucsf.edu. 